\title{
Estimation of the Treatment Effects of Ownership on the Indirect Financing of Small- and Medium-Sized Enterprises
}

\author{
Xiuzhen Wang, ${ }^{1}$ Yi Hu, ${ }^{2}$ Xiaohua Xia, ${ }^{3}$ and Ying Deng ${ }^{4}$ \\ ${ }^{1}$ School of Economics and Management, Beijing Jiaotong University, Beijing 100044, China \\ ${ }^{2}$ School of Management, University of Chinese Academy of Sciences, Beijing 100190, China \\ ${ }^{3}$ Institute of China's Economic Reform and Development, Renmin University of China, Beijing 100872, China \\ ${ }^{4}$ School of International Trade and Economics, University of International Business and Economics, Beijing 100029, China
}

Correspondence should be addressed to Yi Hu; huyi@ucas.ac.cn

Received 17 April 2014; Accepted 7 July 2014; Published 16 July 2014

Academic Editor: Chuangxia Huang

Copyright (C) 2014 Xiuzhen Wang et al. This is an open access article distributed under the Creative Commons Attribution License, which permits unrestricted use, distribution, and reproduction in any medium, provided the original work is properly cited.

\begin{abstract}
Small- and medium-sized enterprises (SMEs) are the important driving forces for the growth of China's economy. However, financing difficulty has always been the important problem besetting the development of SMEs for a long time. In particular, in recent years, US subprime crisis in 2008 caused a heavy blow to the development of some externally oriented SMEs. Thus, how to effectively overcome financing predicament for the SMEs is crucial for Chinese government. In this paper, based on microdata from China Industrial Enterprise Database, propensity score matching (PSM) method is adopted to conduct empirical analysis about the treatment effects of indirect financing level of SMEs under different systems. Empirical results reveal that state-owned enterprises enjoy indirect financing advantages compared with other enterprises and there is certain ownership discrimination against foreign-funded enterprises and private enterprises. In particular, the indirect financing rate of state-owned enterprises is $1.4 \%$ higher than that of other enterprises, and the indirect financing rate of foreign-funded enterprises is $6 \%$ lower than that of other enterprises; private enterprises are advantageous in indirect financing compared with other enterprises; however, indirect financing rate of private enterprises is $1.8 \%$ lower than that of state-owned enterprises, which also reveals ownership discrimination to certain extent.
\end{abstract}

\section{Introduction}

Small- and medium-sized enterprises (SMEs) play a decisive role in developing national economy. However, their development is confronted with many difficulties. In particular US subprime crisis in 2008 triggered global economic recession, causing a heavy blow to the survival, operation, and development of some externally oriented SMEs [1-3]. Thus how to help SMEs resolve economic difficulty, enable healthy growth of SMEs, especially how to effectively overcome financing predicament for them, remove financing barriers, and improve financing efficiency is currently one important subject and pressing task for China.

Financing difficulty has always been the important problem baffling the development of SMEs for a long time [46]. Though the government and financial institutions have made great efforts in improving financing services for SMEs, financial resources from formal financial system, for example, stock market, for SMEs are still much lower than economic contributions made by SMEs [7-10]. According to statistical data from National Development and Reform Commission, the number of SMEs registered with industrial and commercial department in China has exceeded 4.80 million, while total number of SMEs including individual businesses in China has surpassed 42 million, accounting for more than $99 \%$ of aggregate number of enterprises nationwide. Jobs provided by SMEs account for more than $75 \%$ of total jobs in cities and towns nationwide and GDP created by SMEs represents $59 \%$ of national GDP; commodities produced by these enterprises make up $60 \%$ of total social sales, while tax payment from them constitutes $51 \%$ of total national tax amount; these enterprises stand for half of national economy. In addition, SMEs also play an important role in scientific and technical innovation activities and have 
become the main body for technologies and innovations in China. Currently, in China, $66 \%$ of patents are invented by SMEs, more than $75 \%$ of technical innovations are completed by SMEs, and new products researched and developed by these enterprises account for $82 \%$ of total ones in China. However, according to 2012 Blue Book of Chinese SMEs, estimation made by China Banking Regulatory Commission showed that bank credit covered $100 \%$ of large enterprises, $90 \%$ of medium-sized enterprises, and only $20 \%$ of small enterprises and almost no microenterprises. Given current economic downturn, commercial banks are more prudential in offering loans and 10\%-15\% of SMEs actually obtain loans. Furthermore, according to data from People's Bank of China, as of September, 2010, only 239,000 SMEs nationwide had acquired banks' intent for credit extension and bank credit covered less than $1 \%$ of SMEs.

Many SMEs cannot but secure financing from informal financial channels in order to address the shortage of capital in China; thus private finance rapidly grows and considerable quantity of bank credit and capital from listed companies also flow to private lending market through various channels. In recent years, with rising labor and land costs in China and unfolding adverse impact from exchange rate reform and international financial crisis on export market for Chinese SMEs, profit margin for SMEs has been narrowed, while high cost of private financing has further exacerbated the difficulties for survival and development of SMEs with relatively low profit margin, which has not only affected continuously stable growth of China's economy but also exerted negative impact on employment, income distribution, economy, and social stability.

Large number of SMEs have gone bankrupt and been closed in China since financial crisis; thus the contradiction in financing difficulty for SMEs has become more acute. The State attaches great importance to the problems for SMEs as the State Council, ministries, and commissions under the State Council have intensively released series of policy measures. In March, 2012, the State Council established pilot financial reform zone in Wenzhou City, Zhejiang Province, with the purpose of exploring the realistic path for further promoting China's financial reform. The State Council promulgated the Opinions on Further Supporting Healthy Development of Small and Microenterprises on April 19, 2012, which intensified support for small and microenterprises. Afterwards, China Banking Regulatory Commission issued the Implementation Opinions on Encouraging and Guiding Entry of Private Capital into the Banking Industry in May, 2012, with the aim of supporting private capital to be invested in financial institutions together with other capitals under equal conditions.

Many scholars take ownership discrimination as one important cause for financing difficulty surrounding SMEs. However, existing research is subject to the following restrictions: firstly, research sample is derived from either questionnaire survey on local areas or annual reports of listed SMEs, data size is very limited, and research conclusions are also exposed to certain limitations. Secondly, the method is dominated by direct regression without considerations for possible endogeneity issue in model and with failure to effectively identify the real causal relationship. Therefore, this paper uses Industrial Enterprise Survey Database of National Bureau of Statistics since this database includes all state-owned enterprises and nonstate-owned industrial enterprises with main business revenue exceeding five million Yuan and extensively covers enterprises, adopts many survey indicators, and can better reflect current situation of Chinese SMEs. Moreover, in this paper, propensity score matching method is employed to study indirect financing for SMEs under different ownerships so as to draw more accurate research conclusions.

The remainder of the paper proceeds as follows: Section 2 introduces the data and variables. Section 3 discusses the propensity score matching method and empirical analysis. Section 4 concludes.

\section{Data and Variables}

2.1. Data. This paper derives data from China Industrial Enterprise Database of National Bureau of Statistics in 2007. This database is developed by National Bureau of Statistics on the basis of statistics concerning all state-owned enterprises and nonstate-owned industrial enterprises with main business revenue exceeding five million Yuan each year. However, part of statistical samples in this database includes mistakes and omissions; thus this paper conducts preliminary screening of data samples under the screening principle: samples "under operation" (namely, operation state $=1$ ) and organizations which are "enterprises" (namely, organization type $=1$ ) are retained, while samples with "annual average number of all employees" less than 5, those with "total assets" less than or equal to 0 , and those with "total current liabilities" less than or equal to 0 as well as those with "total industrial output value (current year's prices)" less than 0 are eliminated.

Reference is made to the standard for classification of SMEs implemented in 2003 so that the screened data is sorted out, and enterprises which concurrently satisfy the conditions that total assets and sales volume do not exceed 400 million and 300 million and the number of employees is not more than 3,000 are classified as SMEs, namely, small- and medium-sized industrial enterprises above the designated scale. This treatment embodies the real meaning of national standard and controls enterprises above certain level as well as is the common way for addressing such issue in relevant domestic and foreign researches.

2.2. Variables. This paper is mainly designed to study indirect financing for enterprises under different ownerships and focuses research on ownership discrimination against state-owned, foreign-funded, and private holding enterprises among SMEs. In this paper, propensity score matching method is used to examine the impact from ownerships on financing for SMEs. This method needs to be based on the following variables.

(1) Independent Variable. Indirect financing rate $(Y)$ is closely related to current liability rate; numerical value of indirect financing cannot be directly 
TABLE 1: Descriptive statistics.

\begin{tabular}{|c|c|c|c|c|c|c|}
\hline \multicolumn{2}{|r|}{ Ownership } & State-owned & Foreign & Private & Others & Total \\
\hline \multicolumn{2}{|r|}{ Obs } & 5124 & 20661 & 126752 & 22502 & 163972 \\
\hline \multirow{4}{*}{$Y$} & Mean & 0.569 & 0.475 & 0.533 & 0.545 & 0.528 \\
\hline & S.D & 0.437 & 0.346 & 0.294 & 0.339 & 0.31 \\
\hline & Min & 0.001 & 0 & 0 & 0 & 0 \\
\hline & $\operatorname{Max}$ & 8.851 & 12.998 & 8.787 & 8.138 & 12.998 \\
\hline \multirow{4}{*}{$X_{1}$} & Mean & 0.659 & 0.499 & 0.574 & 0.597 & 0.569 \\
\hline & S.D & 0.483 & 0.351 & 0.29 & 0.346 & 0.312 \\
\hline & Min & 0.001 & 0 & 0 & 0 & 0 \\
\hline & $\operatorname{Max}$ & 14.662 & 12.998 & 8.787 & 8.144 & 14.662 \\
\hline \multirow{4}{*}{$X_{2}$} & Mean & 19.294 & 6.818 & 6.348 & 14.151 & 7.356 \\
\hline & S.D & 15.731 & 4.781 & 6.385 & 10.133 & 7.601 \\
\hline & Min & 0 & 0 & 0 & 0 & 0 \\
\hline & Max & 100 & 107 & 169 & 69 & 169 \\
\hline \multirow{4}{*}{$X_{3}$} & Mean & 218.024 & 237.323 & 297.727 & 277.132 & 286.189 \\
\hline & S.D & 325.562 & 288.706 & 293.513 & 1088.525 & 404.459 \\
\hline & Min & 0.069 & 0.353 & 0.167 & 0.273 & 0.069 \\
\hline & Max & 9008.5 & 11301.176 & 8944.077 & 112290 & 112290 \\
\hline \multirow{4}{*}{$X_{4}$} & Mean & 236.331 & 216.215 & 195.298 & 204.726 & 199.873 \\
\hline & S.D & 306.038 & 279.792 & 221.966 & 241.806 & 234.618 \\
\hline & Min & 1.333 & 1.022 & 0.452 & 1.473 & 0.452 \\
\hline & Max & 7805.4 & 6782.2 & 6986 & 5080 & 7805.4 \\
\hline
\end{tabular}

obtained; this paper adopts the ratio of current liabilities to total assets as indirect financing rate.

(2) Treatment Variables. This paper considers the following three treatment variables: dummy variables as to whether they are state-owned holding enterprises $\left(D_{1}\right)$, foreign-funded holding enterprises $\left(D_{2}\right)$, and private holding enterprises $\left(D_{3}\right)$.

(3) Characteristic Variables. The following control variables concerning enterprise characteristics are considered: asset-liability ratio $\left(X_{1}\right.$, ratio of total liabilities to total assets), enterprise age $\left(X_{2}\right.$, years from enterprise establishment to 2007), labor productivity $\left(X_{3}\right.$, ratio of total industrial output value to the number of employees), and capital intensity $\left(X_{4}\right.$, ratio of total assets to number of employees).

Table 1 provides the result of descriptive statistics about the above variables grouped on the basis of actual holding.

According to the result of descriptive statistics in Table 1, enterprises under different ownerships show marked differences in production and operation. State-owned holding enterprises enjoy relatively high indirect financing rate, while foreign-funded holding enterprises have relatively low indirect financing rate. Meanwhile, state-owned holding enterprises indicate the highest asset-liability ratio, while foreign-funded holding enterprises present the lowest assetliability ratio. Current liabilities form the important part of total liabilities and serve as the important yardstick for measuring indirect financing; thus asset-liability ratio and indirect financing rate have exactly the same size relationship among enterprises under different ownerships. From the perspective of labor productivity, state-owned holding enterprises reveal the lowest efficiency, while private holding enterprises exhibit relatively high efficiency. Foreign-funded holding enterprises have the highest capital intensity, while private enterprises show the lowest capital intensity, which also reflect the disadvantages of private holding enterprises in capital.

Table 1 only gives expression to differences in simple average values of indirect financing rates among enterprises under different ownerships and does not control the impact from other factors. Subsequently, ordinary least squares (OLS) regression is performed for basic econometrical models composed of the above variables; the models are given in the following:

$$
\begin{aligned}
& Y_{i}=C+X_{1 i} \beta_{1}+X_{2 i} \beta_{2}+X_{3 i} \beta_{3}+X_{4 i} \beta_{4}+T_{1 i} \gamma_{1}+\varepsilon_{i} \\
& Y_{i}=C+X_{1 i} \beta_{1}+X_{2 i} \beta_{2}+X_{3 i} \beta_{3}+X_{4 i} \beta_{4}+T_{2 i} \gamma_{2}+\varepsilon_{i} \\
& Y_{i}=C+X_{1 i} \beta_{1}+X_{2 i} \beta_{2}+X_{3 i} \beta_{3}+X_{4 i} \beta_{4}+T_{3 i} \gamma_{3}+\varepsilon_{i}
\end{aligned}
$$

in which, $\gamma_{1}, \gamma_{2}$, and $\gamma_{3}$ measure the magnitudes of treatment effect.

The ordinary least squares regression result shown in Table 2 .

As indicated by estimation results (1), (2), and (3) in Table 2, subject to controlling asset-liability ratio, enterprise age, labor productivity and capital intensity, and so forth, indirect financing rate of foreign-funded holding enterprises is higher than that of nonforeign-funded holding enterprises, while that of state-owned holding enterprises is lower than that of nonstate-owned holding enterprises, and estimation 
TABLE 2: Ordinary least squares estimation (1).

\begin{tabular}{|c|c|c|c|}
\hline & Model (1) & Model (2) & Model (3) \\
\hline \multirow{2}{*}{$X_{1}$} & $0.921^{* * *}$ & $0.921^{* * *}$ & $0.920^{* * *}$ \\
\hline & (973.07) & $(969.86)$ & $(970.12)$ \\
\hline \multirow{2}{*}{$X_{2}$} & $-0.412^{* * *}$ & $-0.641^{* * *}$ & $-0.653^{* * *}$ \\
\hline & $(-10.17)$ & $(-16.49)$ & $(-16.27)$ \\
\hline \multirow{2}{*}{$X_{3}$} & $0.0555^{* * *}$ & $0.0665^{* * *}$ & $0.0597^{* * *}$ \\
\hline & $(7.11)$ & $(8.5)$ & $(7.63)$ \\
\hline \multirow{2}{*}{$X_{4}$} & $-0.152^{* * *}$ & $-0.172^{* * *}$ & $-0.164^{* * *}$ \\
\hline & $(-11.29)$ & $(-12.83)$ & $(-12.17)$ \\
\hline \multirow{2}{*}{$T_{1}$} & $-0.0380^{* * *}$ & & \\
\hline & $(-21.57)$ & & \\
\hline \multirow{2}{*}{$T_{2}$} & & $0.0123^{* * *}$ & \\
\hline & & (13.84) & \\
\hline \multirow{2}{*}{$T_{3}$} & & & $6.72 E-05$ \\
\hline & & & $(0.09)$ \\
\hline \multirow{2}{*}{ Constant } & $0.00987^{* * *}$ & $0.00864^{* * *}$ & $0.0109^{* * *}$ \\
\hline & $(13.62)$ & $(11.65)$ & (11.49) \\
\hline$N$ & 163972 & 163972 & 163972 \\
\hline
\end{tabular}

results about private holding enterprises are insignificant. This means that state-owned holding enterprises are subject to ownership discrimination from indirect financing. Such results are exactly opposite to descriptive statistical analysis in Table 1. Furthermore, given possible endogeneity in assetliability ratio, regressions are reconducted after such variable is deleted; the modified models are given by

$$
\begin{gathered}
Y_{i}=C+X_{2 i} \beta_{2}+X_{3 i} \beta_{3}+X_{4 i} \beta_{4}+T_{1 i} \gamma_{1}+\varepsilon_{i}, \\
Y_{i}=C+X_{2 i} \beta_{2}+X_{3 i} \beta_{3}+X_{4 i} \beta_{4}+T_{2 i} \gamma_{2}+\varepsilon_{i}, \\
Y_{i}=C+X_{2 i} \beta_{2}+X_{3 i} \beta_{3}+X_{4 i} \beta_{4}+T_{3 i} \gamma_{3}+\varepsilon_{i} .
\end{gathered}
$$

With the estimation results shown in Table 3.

It is observed that, after enterprise age, labor productivity, capital intensity, and so forth are controlled; indirect financing rate of state-owned holding enterprises is higher than that of nonstate-owned holding enterprises, while indirect financing rate of foreign-funded holding enterprises is lower than that of nonforeign-funded holding enterprises and that of private enterprises is significantly higher than that of nonprivate enterprises. Results are exactly contrary to (1), (2), and (3). Given instability of results, the following section of this paper adopts propensity score matching method to accurately estimate the impact from ownership factor on indirect financing rates of SMEs.

\section{Propensity Score Matching Method and Empirical Analysis}

3.1. Propensity Score Matching Method. Econometrical analysis in the above section indicates that difference in ownership form indeed results in changes in indirect financing rates of
TABLE 3: Ordinary least squares estimation (2).

\begin{tabular}{lccc}
\hline & Model (4) & Model (5) & Model (6) \\
\hline \multirow{2}{*}{$X_{2}$} & $2.43^{* * *}$ & $2.44^{* * *}$ & $3.01^{* * *}$ \\
& $(23.16)$ & $(24.22)$ & $(29.05)$ \\
\hline \multirow{2}{*}{$X_{3}$} & -0.0174 & $-0.0509^{* *}$ & $-0.0414^{* *}$ \\
& $(-0.86)$ & $(-2.51)$ & $(-2.04)$ \\
\hline \multirow{2}{*}{$X_{4}$} & $-0.270^{* * *}$ & $-0.225^{* * *}$ & $-0.225^{* * *}$ \\
& $(-7.74)$ & $(-6.44)$ & $(-6.43)$ \\
\hline \multirow{2}{*}{$T_{1}$} & $0.0130^{* * *}$ & & \\
\hline \multirow{2}{*}{$T_{2}$} & $(2.84)$ & $-0.0592^{* * *}$ & \\
& & $(-25.69)$ & $0.0373^{* * *}$ \\
\multirow{2}{*}{$T_{3}$} & \multicolumn{3}{c}{$0.483^{* * *}$} \\
& \multicolumn{3}{c}{$0.523^{* * *}$} \\
\multirow{2}{*}{ Constant } & $0.515^{* * *}$ & $(388.66)$ & $(228.98)$ \\
\hline$N$ & $(392.15)$ & 163972 & 163972 \\
\hline$* * * * * *$ indicates statistical significance at the $1 \%, 5 \%$, and $10 \%$ significance
\end{tabular}
level, respectively. The $t$ statistics are given in parenthesis.

enterprises. However, we should also pay attention to possible endogeneity issue between ownership form and indirect financing rate. In order to eliminate sample selectivity bias, this section uses propensity score matching (PSM, [11-14]) method to address such issue. Take whether enterprises are state-owned holding ones as an example, core philosophy of this method lies in identifying the difference in indirect financing rates of one enterprise between "state-owned holding" and "nonstate-owned holding"; given that such difference involves one enterprise under different ownership forms, we can confirm that such difference is caused by change in ownership form and there is no endogeneity issue that indirect financing rate of state-owned holding enterprise itself is relatively high or relatively low. However, as no "nonstate-owned holding" condition exists in state-owned holding enterprises, we need to find nonstate-owned holding enterprises "similar" to state-owned holding enterprises and study nonstate-owned holding enterprises to judge whether indirect financing rate of state-owned holding enterprises is increased so as to obtain average treatment effect (ATE) concerning the impact of different ownership forms on indirect financing rates of enterprises. Specifically, we firstly estimate the determining equation as to whether enterprises are state-owned ones:

$$
\operatorname{PS}(X)=P(D=1 \mid X)=E(T \mid X),
$$

where $D$ is indicative variable, if it is 1 , it means state-owned holding, and if it is 0 , it represents nonstate-owned holding; $X$ means the factor which affects whether enterprise selects state-owned holding. PS is the probability that enterprise selects state-owned holding, namely, propensity score. Based on (1), propensity score $\operatorname{PS}\left(X_{i}\right)$ of each enterprise $i$ can be 
TABLE 4: Average treatment effects (matching estimators).

\begin{tabular}{|c|c|c|c|c|c|c|}
\hline & & Treated & Controls & ATT & S.E. & $t$-stat \\
\hline \multirow{2}{*}{$D_{1}$} & Unmatched & 0.569 & 0.527 & $0.042^{* * *}$ & 0.004 & 9.570 \\
\hline & ATT & 0.569 & 0.555 & $0.014^{* *}$ & 0.007 & 2.020 \\
\hline \multirow{2}{*}{$D_{2}$} & Unmatched & 0.475 & 0.536 & $-0.061^{* * *}$ & 0.002 & -26.420 \\
\hline & ATT & 0.475 & 0.535 & $-0.060^{* * *}$ & 0.003 & -20.910 \\
\hline \multirow{2}{*}{$D_{3}$} & Unmatched & 0.533 & 0.509 & $0.024^{* * *}$ & 0.002 & 13.220 \\
\hline & ATT & 0.533 & 0.501 & $0.033^{* * *}$ & 0.003 & 12.550 \\
\hline \multirow{2}{*}{$D_{3}{ }^{*}$} & Unmatched & 0.533 & 0.569 & $-0.035^{* * *}$ & 0.004 & -8.250 \\
\hline & ATT & 0.533 & 0.552 & $-0.018^{*}$ & 0.011 & -1.660 \\
\hline
\end{tabular}

${ }^{* * *, * * * *}$ indicates statistical significance at the $1 \%, 5 \%$, and $10 \%$ significance level, respectively.

calculated. Based on Becker and Ichino [11], average treatment effect concerning state-owned holding and nonstateowned holding for indirect financing rates of enterprises can be obtained:

$$
\begin{aligned}
\mathrm{ATT} & =E\left[Y_{1 i}-Y_{0 i} \mid D_{i}=1\right] \\
& =E\left\{E\left[Y_{1 i}-Y_{0 i} \mid D_{i}=1, p\left(X_{i}\right)\right]\right\},
\end{aligned}
$$

where $Y_{1 i}$ and $Y_{0 i}$ separately represent indirect financing rates of individual $i$ under both conditions: state-owned holding and nonstate-owned holding.

In actual analysis, average treatment effect is generally calculated through the following three steps.

Step 1. Logit model is used to estimate propensity score:

$$
\operatorname{PS}\left(X_{i}\right)=P\left(D_{i}=1 \mid X_{i}\right)=\frac{\exp \left(X_{i}^{\prime} \beta\right)}{1+\exp \left(X_{i}^{\prime} \beta\right)}
$$

Fitted value $\widehat{\operatorname{PS}}\left(X_{i}\right)$ (namely, propensity score) is obtained.

Step 2 (Matching). PS $(X)$ is continuous variable; thus it is very difficult to conduct exact matching for it. Common inexact matching methods include one-to-one matching, $k$ nearest neighbors matching, radius matching, and kernel matching. As sample size in this paper is very large, it takes excessively long time to adopt the latter two ones which are unfeasible in practice. This paper uses $k$-nearest neighbors matching. Matching rules are shown below:

$$
\left|\mathrm{PS}_{i}-\mathrm{PS}_{j}\right|=\min _{k \in\{D=0\}}\left\{\left|\mathrm{PS}_{i}-\mathrm{PS}_{k}\right|\right\}
$$

Step 3. According to the matching results, average treatment effect is calculated as follows:

$$
\operatorname{ATT}=\frac{1}{N^{T}} \sum_{i \in T}\left[Y_{i}^{T}-\sum_{j \in C(i)} \omega_{i j} Y_{j}^{C}\right]
$$

in which $Y_{i}^{T}$ and $Y_{j}^{C}$ are the outcomes of treated individual $i$ and control individual $j$, respectively. $\omega_{i j}$ is the weight.

3.2. Empirical Analysis. After nonstate-owned holding enterprises which match with state-owned holding enterprises are identified through the above method, propensity score matching method is adopted to calculate the difference in average indirect financing rates between two groups of enterprises; final results are shown in $D_{1}$ in Table 4 . The matching processes for foreign-funded holding and private holding enterprises are similar to the above process; their final results are indicated in $D_{2}$ and $D_{3}$ in Table 4 . The estimation results to which we mainly pay attention in these tables are average treatment effects on the treated (ATT) which means the difference in indirect financing rates of enterprises between treatment group and control group.

According to Table 4, with respect to $D_{1}$, in terms of state-owned and nonstate-owned enterprises, indirect financing rate of state-owned enterprises is $4.2 \%$ higher than that of nonstate-owned enterprises before treatment; after treatment, indirect financing rate of state-owned enterprises is still but only $1.4 \%$ higher than that of nonstate-owned enterprises. With respect to $D_{2}$, in terms of foreign-funded and nonforeign-funded enterprises, indirect financing rate of foreign-funded enterprises is $6 \%$ lower than that of nonforeign-funded enterprises both before and after treatment, which suggests that foreign-funded enterprises are disadvantageous in indirect financing. With regard to $D_{3}$, in terms of private and nonprivate enterprises, indirect financing rate of private enterprises is $2.4 \%$ and $3.3 \%$ higher than that of nonprivate enterprises before and after treatment.

However, it is worth noting that indirect financing rate of private enterprises is $3.5 \%$ lower before treatment. In order to further study whether there is discrimination against private enterprises compared with state-owned enterprises, sample size is limited to state-owned enterprises and private enterprises, and propensity score matching estimation is reconducted, with the result shown in $D_{3}{ }^{*}$, which shows that indirect financing rate of private enterprises is $1.8 \%$ lower than that of state-owned enterprises after treatment. The corresponding value $t$ is -1.66 , and it is significant at $10 \%$ significant level. This means that private enterprises are also subject to certain ownership discrimination in indirect financing compared with state-owned enterprises. 


\section{Conclusions}

This paper utilizes China Industrial Enterprise Database of National Bureau of Statistics and makes reference to the standard for classification of SMEs implemented in 2003 for screening samples of SMEs and studying the difference in indirect financing among SMEs under different ownership systems. As indicated by regression result, results greatly vary with different control variables. Propensity score matching method is further adopted to perform estimation and discover that state-owned enterprises enjoy advantages in indirect financing compared with other enterprises, and indirect financing rate is $1.4 \%$ higher than that of other enterprises. Foreign-funded enterprises are faced with ownership discrimination in indirect financing, and their indirect financing rate is $6 \%$ lower than that of other enterprises. Private enterprises are advantageous in indirect financing compared with other enterprises. However, indirect financing rate of private enterprises is $1.8 \%$ lower than that of state-owned enterprises, which also reveals ownership discrimination to certain extent.

\section{Conflict of Interests}

The authors declare that there is no conflict of interests regarding the publication of this article.

\section{Acknowledgment}

This work was partially supported by the National Natural Science Foundation of China (Grant nos. 71301160 and 71203224) and China Postdoctoral Science Foundation funded project (Grant nos. 2012M520420).

\section{References}

[1] F. H. Wen, Z. F. He, and X. H. Chen, "Investors risk preference characteristics and conditional skewness," Mathematical Problems in Engineering, vol. 2014, Article ID 814965, 14 pages, 2014.

[2] C. Huang, C. Peng, X. Chen, and F. Wen, "Dynamics analysis of a class of delayed economic model," Abstract and Applied Analysis, vol. 2013, Article ID 962738, 12 pages, 2013.

[3] F. H. Wen, Z. F. He, X. Gong, and A. M. Liu, "Investors'risk preference characteristics based on different reference point," Discrete Dynamics in Nature and Society, vol. 2014, Article ID 158386, 9 pages, 2014.

[4] J. Lopez-Gracia and C. Aybar-Arias, "An empirical approach to the financial behaviour of small and medium sized companies," Small Business Economics, vol. 14, no. 1, pp. 55-63, 2000.

[5] D. Czarnitzki, "Research and development in small and medium-sized enterprises: the role of financial constraints and public funding," Scottish Journal of Political Economy, vol. 53, no. 3, pp. 335-357, 2006.

[6] D. Czarnitzki and H. Hottenrott, "R\&D investment and financing constraints of small and medium-sized firms," Small Business Economics, vol. 36, no. 1, pp. 65-83, 2011.

[7] F. Wen and Z. Liu, "A copula-based correlation measure and its application in Chinese stock market," International Journal of Information Technology and Decision Making, vol. 8, no. 4, pp. 787-801, 2009.
[8] F. Wen and X. Yang, "Skewness of return distribution and coefficient of risk premium," Journal of Systems Science \& Complexity, vol. 22, no. 3, pp. 360-371, 2009.

[9] C. X. Huang, X. Gong, X. H. Chen, and F. H. Wen, "Measuring and forecasting volatility in Chinese stock market using HARCJ-M model," Abstract and Applied Analysis, vol. 2013, Article ID 143194, 13 pages, 2013.

[10] F. H. Wen, X. Gong, Y. C. Chao, and X. H. Chen, "The effects of prior outcomes on risky choice: evidence from the stock market," Mathematical Problems in Engineering, vol. 2014, Article ID 272518, 8 pages, 2014.

[11] S. Becker O and A. Ichino, "Estimation of average treatment effects based on propensity scores," The Stata Journal, vol. 2, no. 4, pp. 358-377, 2002.

[12] R. H. Dehejia and S. Wahba, "Propensity score-matching methods for nonexperimental causal studies," Review of Economics and Statistics, vol. 84, no. 1, pp. 151-161, 2002.

[13] A. Abadie and G. W. Imbens, "Large sample properties of matching estimators for average treatment effects," Econometrica, vol. 74, no. 1, pp. 235-267, 2006.

[14] M. Caliendo and S. Kopeinig, "Some practical guidance for the implementation of propensity score matching," Journal of Economic Surveys, vol. 22, no. 1, pp. 31-72, 2008. 


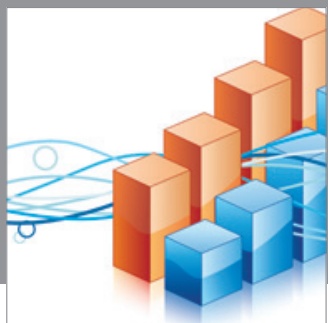

Advances in

Operations Research

mansans

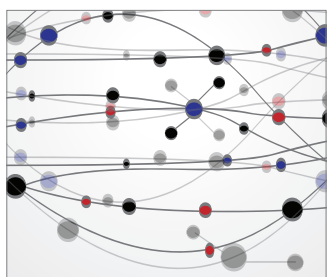

The Scientific World Journal
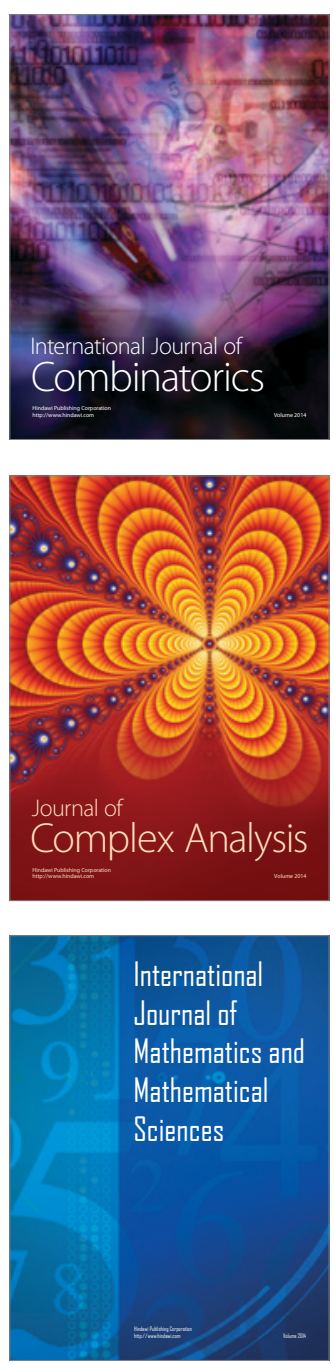
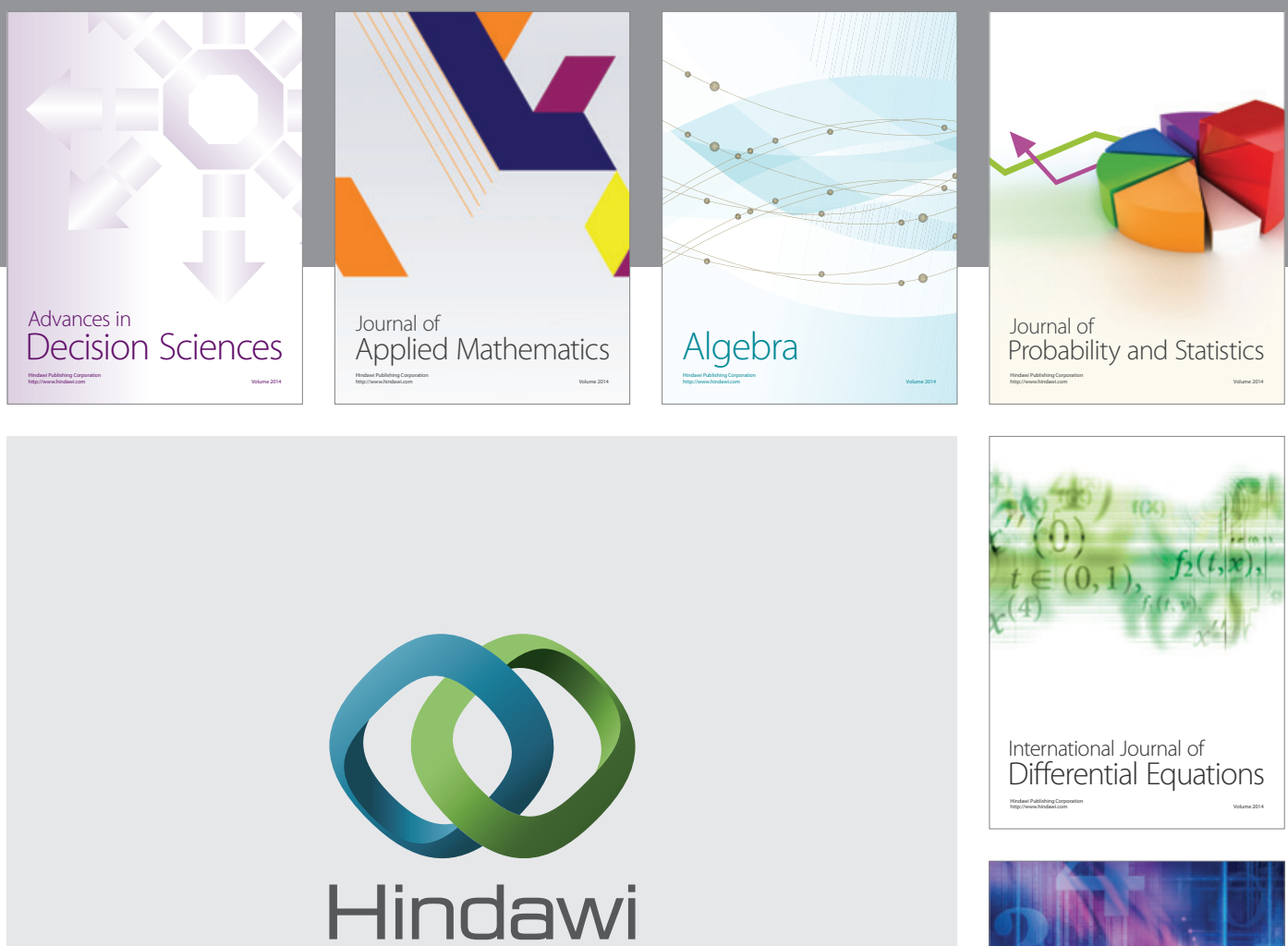

Submit your manuscripts at http://www.hindawi.com
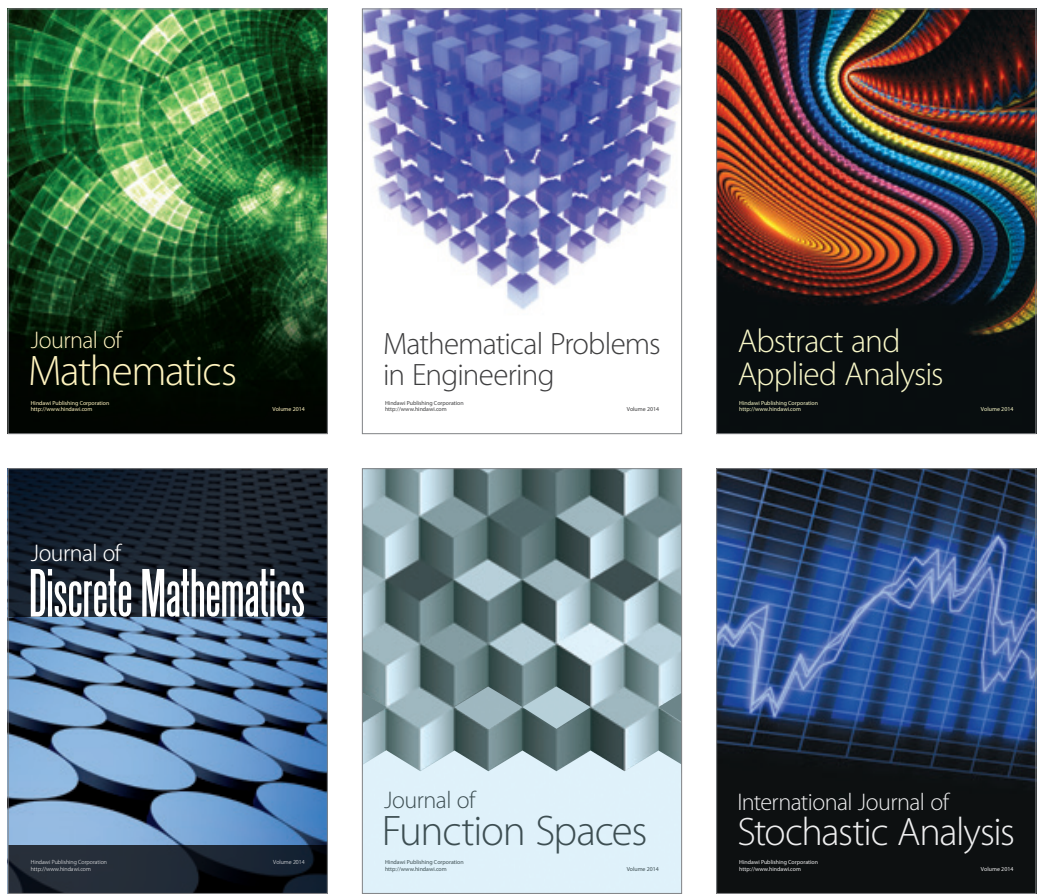

Journal of

Function Spaces

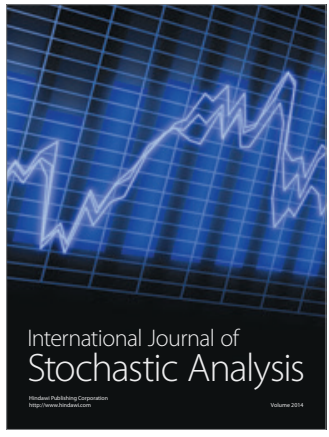

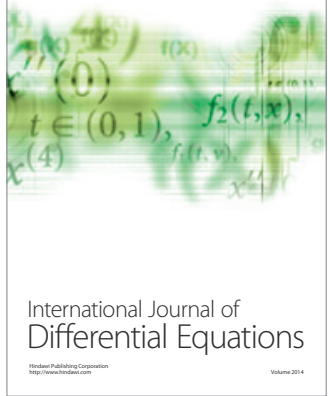
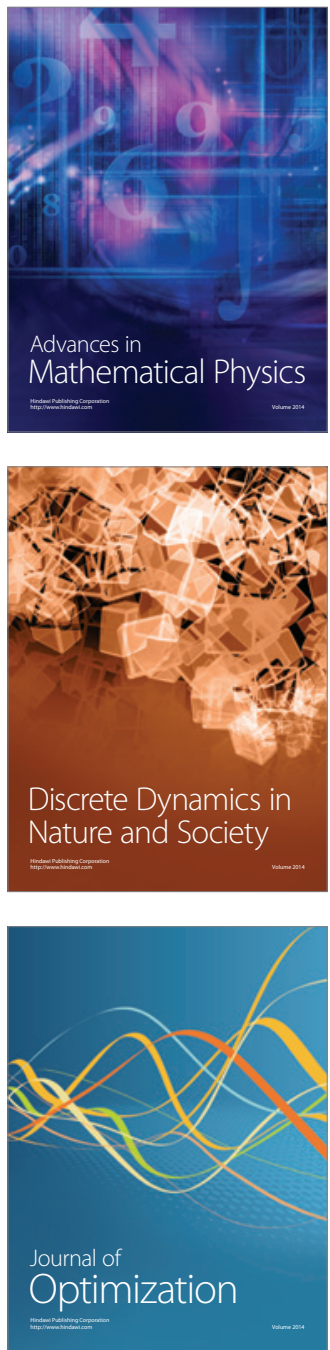